\title{
Farmers' Experiences as Victims of Crime: An Exploratory Study on the Isle of Anglesey
}

Dr Tim Holmes

School of Social Sciences

Bangor University

Bangor

LL57 2DG

Dr Jane Jones

Miles Centre

Bangor University

Bangor

LL57 2DG

Tim Holmes Contact author: t.holmes@bangor.ac.uk; +44 (01248 383299)

\begin{abstract}
Farming is not only a profession, for many it is a lifestyle. Farmers' place of work is often their home and this reality poses several questions about the challenges farmers face with regard to dealing with victimisation and creating an effective crime prevention strategy. This paper reports on the findings of an exploratory study of farmers' views on the Isle of Anglesey. A mixed method design was used based on postal surveys and interviews, to explore farmers' experiences as victims of crime, and opinions on the support provided by local government agencies, the police, and the community. Findings suggest that farmers had minimal experience as victims of crime, which resulted in complacency towards crime prevention and reliance on the local community to identify trustworthy employees and potential crime threats.
\end{abstract}

\section{Keywords: farms, crime prevention, rural crime, victimisation}




\section{Introduction}

This study is an examination of victimisation in the farming communities of the Isle of Anglesey (see map, Figure 1). A survey was distributed to farmers on Anglesey followed by twenty semi-structured interviews asking farmers about any crimes that had been committed against their farms. Through this study we sought to establish how much victimisation farmers on Anglesey experienced and their attitudes towards crime and crime prevention. The Isle of Anglesey was selected as the geographical focus of this study. Anglesey is an island off the North West coast of Wales with a population of approximately 68,900 which makes it one of the lesser populated regions of the country(National Assembly for Wales Commission 2008: 1). Of this population 60 percent are Welsh speakers which is significantly higher than the rest of Wales which averages at 21 percent. Across the island there are several established farming communities whose experiences and views we sought to research.

The area can be characterised as rural and accessible with significant transport routes across the island to the rest of the UK (via 2 road and train bridges) and to Ireland (via the Port in Holyhead). This accessibility coupled with the existence of several rural communities across the island creates an interesting research environment for the study of crime and victimisation.

Prior studies of rural crime in America, Australia and the United Kingdom (Anderson and McCall, 2005; Barclay, 2001; Donnermeyer and Barclay, 2005; Jones, 2008; Mears et al, 2007) and have explored the nature of rural crime noting common characteristics. Theft of livestock, property (such as vehicles, tools, agricultural supplies) and fuel are often highlighted as key concerns in relation to rural crime, as is vandalism.

An initial study of farm crime was conducted on the Isle of Anglesey in 2008 (Jones 2008), and in 2011 a Farm Watch scheme was re-introduced to the Isle of Anglesey alongside other crime prevention measures to tackle farm crime at a physical level (Jones 2011). The findings of these studies of rural crime produced several questions relating to the perspective farmers had of crime in the area; in particular, their views about being a victim of crime, their potential to be victimised and the need to implement crime prevention strategies.

According to Jones (2010) traditionally crime has been perceived as a largely urban problem and the countryside in contrast has been viewed as a 'rural idyll' with little crime, the reality is that such imagery has acted to mask the issue of rural crime up until more recent times. The Home Office in 2009 noted that businesses in rural areas are affected by the same types of crime as experienced elsewhere, both physically and technologically.

One estimate by the National Farmers Union insurance company placed claims for theft of 
property excluding tractors at $£ 11.5$ million a year (NFU Mutual, 2004). Carcach (2002) has pointed out that agricultural crime is expensive not only to the individual farmer but also in the wider context because it reverberates outwards into escalating food and insurance costs.

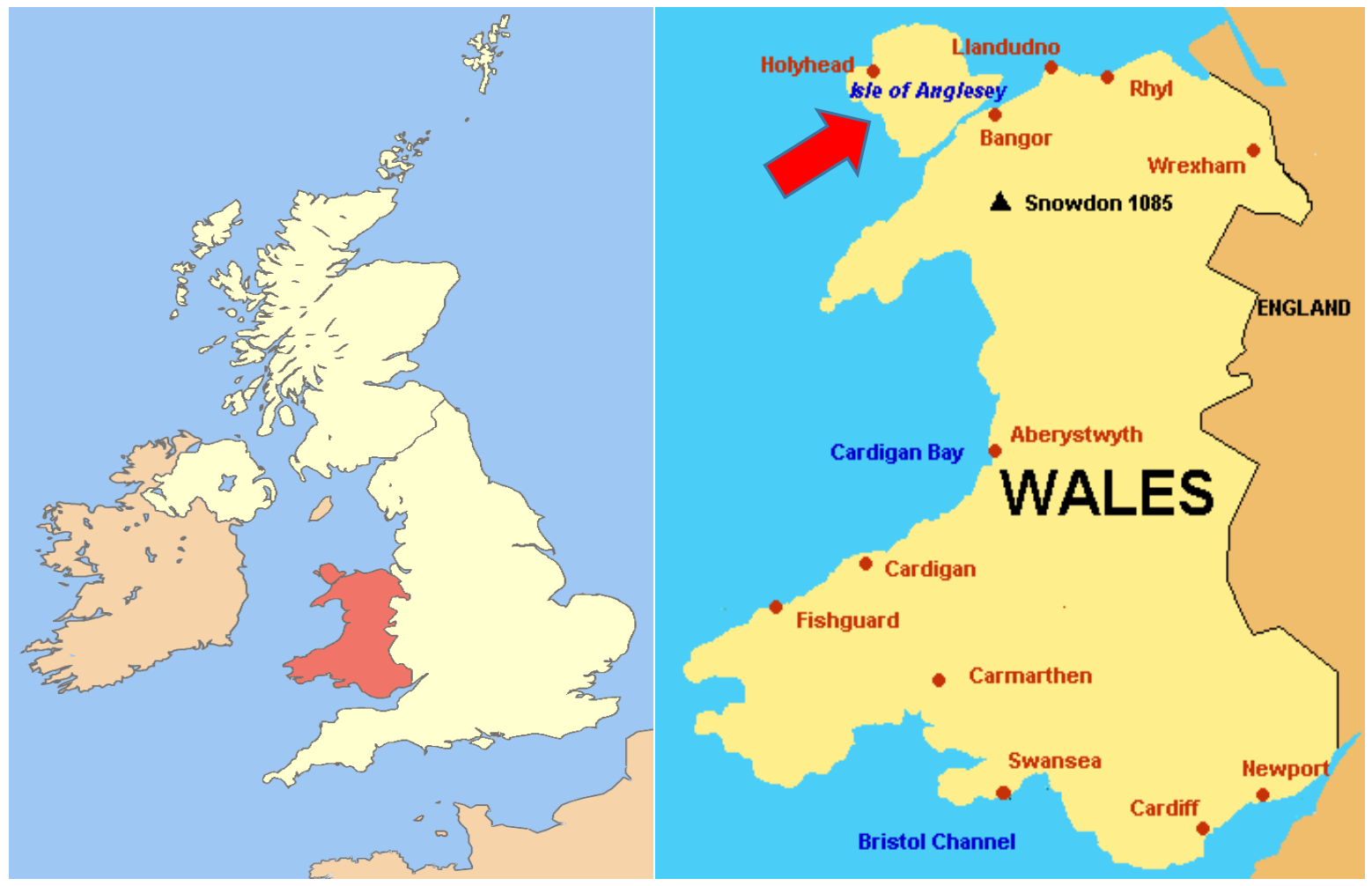

Figure 1: Map of UK, Wales, and the Isle of Anglesey (Atlas of Wales, 2015)

Within this study farmers' experiences of victimisation were primarily discussed in the context of crimes against the farm rather than adopting a broader definition of criminal activity which would include interpersonal violence. The rationale for this was that we wanted to also explore what crime prevention strategies farmers employed to protect their homes and businesses. This also allowed for the inclusion of respondents who had not been directly victimised but had views on their potential to be victimised and their crime prevention strategies.

Tönnies’ (1963 cited in Bouffard and Muftíc 2006) research into rural communities argued that rural communities involved more personal interactions between community members, with a greater number of community members having intimate or personal relationships with each other. This suggests that even if respondents were not directly victimised they could have an awareness of others in the community who had been. In the context of Anglesey the rural communities present on the island exhibited signs of this in particular with regard to crime threats, business practices and attitudes towards those perceived as 'outsiders' or 'strangers'. 
Farm based enterprises conducting more traditional operations and/or diversified enterprises presented a challenge in terms of the data known about their possible crime victimisation and everyday business activities. The recording of farm crime for example, is not necessarily recorded under a farm location and neither is it recorded as crimes against businesses (Jones 2011). Information about the extent of farm based enterprises and their diversification on Anglesey was also difficult to assess unless the business had been registered with organisations such as Farming Connect, Menter Busnes and Menter Môn. These challenges raised questions about the relationship farmers had with local police and government agencies. Therefore, this study operated with four primary aims:

- explore the known crime threats posed to farmers on the Isle of Anglesey

- investigate what crime prevention strategies farmers implemented on their properties

- identify any gaps in crime prevention strategies farmers implemented on their properties

- establish how much engagement farmers had with support services offered by local government and the police

\section{Methodology}

A multi-method research design was used in this project. Data was obtained from both a questionnaire survey in stage one and from this a sample for a series of semi-structured qualitative interviews with farmers was formed to be conducted in stage two.

Organisations operating on the Isle of Anglesey with access to farm based enterprises were used to create a sampling frame: Anglesey county council, Menter Mon, the National Farmers Union (NFU) and the Farmers Union of Wales (FUW). Through contacts in these organisations, the authors compiled a list of farm based enterprises who were either registered with the unions or engaged in European agricultural grant applications (through Menter Mon). This collection of contacts was confirmed and expanded on through the use of 192.com website that provided addresses for individuals and businesses. A sampling frame of a 134 contacts was formed.

The survey was designed to gain biographical data on respondents and their businesses. In the questionnaire respondents were also invited to volunteer to participate in the interview stage of the study. This approach of using an explanatory sequential design meant the study could gain insights into several topics, including the size of enterprises on Anglesey, the different types of businesses being operated on farms, and the respondent's views to what types of crime they were at risk. The level of computer use respondents were engaged in was discussed in the questionnaire in order to examine how much e-crime might be an issue for respondents.

A charitable donation of one pound to the Farm Crisis Network for every returned questionnaire was used as an incentive to respond. Prior to distribution of the survey the project 
was publicized in a local newspaper; 59/134 (44\%) responses were received 56 complete responses were analysed.

Twenty survey respondents who volunteered to take part in the interview stage were selected based upon their geographical location on the Isle of Anglesey. The island was split into four regions - north $(n=5)$, east $(n=8)$, south $(n=2)$ and west $(n=5)$ to provide representative responses from across Anglesey. Poor response rates from farmers in the south of Anglesey were recorded with higher than anticipated responses from the east. This variation in response, did not limit the information available on farmer's experiences, with all geographical areas being covered.

The interview schedule used during the second stage of the project involved discussion of four key subjects, experiences as a victim of crime, the crime prevention strategies respondents used, developments in their businesses (such as data storage strategies) and views on the support available from local agencies. Through these topics it was possible to examine both respondent's actual experiences, perceptions of crime, and their strategies to deal with any potential crime threats.

\section{Findings}

\section{Survey results}

The majority of survey respondents were owners of the farms they worked $(89.28 \%)$, a small minority were tenant farmers $(7.14 \%)$ or managers $(3.57 \%)$. During the interview stage the majority of respondents who agreed to take part were owners with only one tenant farmer agreeing to be interviewed. There was a spread of ages represented in the survey response, the vast majority of survey respondents were aged between fifty-one and seventy. During the interview stage, several respondents voiced the opinion that the financial cost of starting up as a farmer was a barrier to younger people entering the industry. The majority of respondents were male $(68.75 \%), 3.57$ percent did not indicate their sex. The results of this stage of the survey indicated that respondents were for the most part older male farmers. Most respondents were engaged in livestock production (80.35\%), the survey did not distinguish between different types of livestock but represented in the interviews were respondents involved in cattle, chicken, goat and sheep production. Of the farmers who took part in the interviews seventeen of the twenty were involved in livestock production. In terms of diversification 35.71 percent of enterprises were single operation businesses these were all livestock producing farms. Slightly over 64 percent $(64.28 \%)$ of the farm based businesses who responded to the survey had diversified their business practices in some way. Arable farming (19.64\%) and operating Bed and Breakfast hotels or Hotels (19.64\%) were popular diversifications for the respondents. 
When asked how long the respondents had been running a farm-based enterprise two respondents noted length of business operations as 'Lifelong' rather than numerically. The mean length of operation was 388.14 months (standard deviation of 211.59). The median was 444 months (range 6-852), an equivalent of thirty-seven years. Only 19.64 percent of respondents noted they worked alone on the business with 80.35 percent of respondents employing staff to work on their farms $(n=56) .60 .71$ percent reported that family members were involved in some way with working on the business; this was explored further during the interview stage. Of the respondents who employed staff, the median number of full time employees was 1 (range: 0-15), part-time employees 0 (range of 0 to 5). The data points toward older males owning an established business with a limited number of staff working with the enterprise.

One section of the survey was devoted to computer use, when asked about the different ways computers were used in the business respondents reported that computers were used for accounting (57.14\%), selling produce (23.21\%), Communicating with clients $(46.42 \%)$, communicating with suppliers $(33.92 \%)$. Nearly 9 percent $(8.92 \%)$ of respondents noted that no computers were used in their business. Nine (16.07\%) respondents noted that computers were used but only to report cattle movement. This option was not offered in the multiple choice question but was reported under the no computer use option to highlight that this was the exclusive use of computers in their business.

The survey concluded with a multiple choice question which examined the perceived risks to their business (see table 1). An option to detail any other risks faced by the business was provided, from which two additional concerns were highlighted - risks posed by anti-wind turbine protests and anti-social behaviour. While the issue of experiences as a victim and perceived risks of victimisation were primarily reviewed during the interview stage; this question was included in the questionnaire in order to gain a wider view of what were perceived as the most serious crime threats. Theft of property and burglary were the most serious concerns for respondents.

\section{Interview data}

Thirty-five respondents indicated on the questionnaire they were willing to be interviewed of which twenty were selected based on geographical location across Anglesey.

The interview schedule focused on four key areas for discussion: experiences as victims of crime, crime prevention strategy employed on their farm, division of responsibilities for crime prevention and farmers views on the support available in the community. 


\section{Table 1: Perceived threats to Farms on Anglesey}

\begin{tabular}{l|cc}
\multicolumn{1}{c|}{ Risks } & Responses & Percent \\
\hline Vandalism & 17 & 30.35 \\
Arson & 20 & 35.71 \\
Burglary of Premises & 35 & 62.50 \\
Theft & 45 & 80.35 \\
Fraud & 15 & 26.78 \\
Cybercrime & 16 & 28.57 \\
Trespass & 14 & 25.00 \\
Dumping Rubbish & 27 & 48.21 \\
Anti-Wind Turbine & 1 & 1.78 \\
Protests & & \\
Anti-Social Behaviour & 1 & 1.78 \\
\hline
\end{tabular}

\section{Experiences as victims of crime}

Respondents noted either being the victim of some form of criminal activity or knowing someone who had been victimized in their local community. Often they would only point to single or isolated incidents with only one respondent reporting a persistent crime threat in the area they lived in. In this instance the farm was located next to a village which had previously established issues with youth offending. This farmer had experienced theft, vandalism of property and fly-tipping (i.e., illegal dumping of trash/rubbish). This caused a raised awareness of crime threats in the area and speculation as to the effect of unemployment on the local community.

“...the place has its own unique set of problems because there isn't employment for half the people there. So, yes, we've had stocks stolen, sheep stolen from here, but we had next door the farm." (018FNC22).

Quad bike theft emerged as a major concern with regard to the theft of machinery more so than larger vehicles such as tractors or four-wheel drive trucks. This finding corresponded with findings from the latest National Farmers Union Mutual rural crime survey (2013), which noted that after the theft of tools, quad bikes were the most commonly targeted items. In cases where livestock had been lost respondents often had difficulty distinguishing between theft and the expected loss of some livestock due to ill health.

“...we've had had the odd sheep disappear over the years. I'm convinced there's a steady sort of trickle. You know the odd one that you can't account for its disappearance. And 
Farmers' Experiences as Victims of Crime: An Exploratory Study on the Isle of Anglesey Holmes and Jones

yeah you know we all know it goes on...on a very small scale really. But it is happening. I know of an instance where I had a lad working for me who was a small farmer and a ram lamb appeared at that other farm again actually. And we caught it and he said, ooh how he said to me you know which is the slanghter house. You know bonus you see. Take it there. 50 or 60 quid something you know. But you know that was his attitude. So one assumes if that had turned up on his place, it'd be gone in a minute." (081FW18)

No respondent who had reported a crime to the police reported getting their property back or being involved in a prosecution of an offender. Also despite detailed discussion of being victims of crime none of the respondents actively sought assistance from victim support services or expressed concern over repeat offending. Many viewed the incidents they had experienced as isolated events and an expected part of running a business. Since all respondents had insurance on their farm property they would often report little concern over crime. They would obtain a crime reference number from the police and recoup their losses. There was minimal interest in pursuing the crimes committed against them or regaining the lost property when it involved farm equipment or livestock. This attitude is in stark contrast to the awareness respondents had of the value of their property and farm based businesses in general.

"But when you go on to big farm like the farm next door, he has to my knowledge, four tractors and they all go in about £30,000 a throw. You're talking real money, aren't you?" (106FE04)

Although respondents acknowledged they were in possession of valuable equipment and livestock, there was an underlying assumption that they would not lose all of it or a substantial amount to crime. This viewpoint was based on the idea that criminals would need to go to considerable effort to steal from them, and that the insurance would cover the cost of any losses. No respondent reported that their business had been the victim of e-crime or experienced issues with regard to loss of personal data. While survey respondents did note the use of computers in their businesses, interview respondents stated that computers were not an important or vital part of their business practice. The majority of interview respondents did not engage in online sales or purchases for their businesses. With regard to data storage, several respondents said that they destroyed old documents by using them as fuel for log burning fires or as bedding for livestock, seeking to ensure that personal data never left the farm in a manner that could be used by a third party.

\section{Crime prevention on the farm}

All respondents noted that their policy towards crime prevention and security was based on a 'common sense' approach which wasn't supported by any training or advice. The interviewees identified visibility of valuable property or resources as something to take into account. 
"No, I would say probably common sense. But based on the fact that we did lose some fencing material that time then, wire, that thing, that sort of thing is never left out on view. It's always put away hoping to stop people having a look around the building. Furthermore, we looked into going somewhere to look for something then. If it's just sitting out on the yard, they could stop, pick it up and gone, it's much easier." (118FW15)

Dogs and motion sensor activated lights emerged as popular approaches to crime prevention with several respondents noting Closed Circuit Television systems as being the next step in improving security. The role of dogs on the farm was an interesting one, no interviewee reported owning a dog specifically for security or as a guard dog, but they did note the presence of a dog often use as a security measure.

"We've been here for 40 years. Very safe place because we always had dogs. And we have dogs that were notorious for barking and they could well have nipped. When the last of that breed went, we've been the victims of crime I think three times." (134FS06)

The issue of protecting farm equipment, livestock and property was often addressed through padlocks and the location of valuable objects such as vehicles or fuel near to the farm. Two farmers noted the loss of vehicles when they were parked away from the farm buildings on fields or by the road. Respondents observed that while security measures could be put in place there was a limit to what could be achieved in terms of crime prevention. For two interviewees, the limits of what they could achieve through crime prevention strategies made them ambivalent about taking security measures too seriously.

"You know you can lock the gate. They can always pull the gate off its hinges" (081FW18).

"We had one rob...not a robbery but some tools, power tools went missing 4 or 5 years ago. ... We may have mentioned it but we never made it public, you know a statement to the police that... Of course, it wasn't really worth it. And we knew really who had done it. Obviously we've never had them back but the total value probably about £100. It was one of these things that you don't go after." (087FE20)

Despite the majority of respondents reporting that the area they lived in was a safe place, they were still vigilant of passers-by who showed an interest in their property. An issue that was explored in several interviews was the activities of travelling salesmen. Several respondents noted that at one time or another they had encountered individuals who would either offer to purchase scrap metal or old machinery or they were selling discounted machinery. One respondent had been defrauded after involving himself in a business transaction with a travelling 
sales person. This experience aside, all other respondents reported that they had no dealings with people who came to their farms to buy or sell equipment, but they had encountered them and had to send them away.

"Somebody could drive in, pick it up and out the other end. So, we certainly used to get people just sort of driving through the yard. You know, if they were looking for somebody, well, you stop. They were clearly just sort of going through to have a look if there was anything around. Perhaps, the fact that there's never anything lying around now they don't come. It may be that, I don't know. But as I say, we always keep the things like that out of sight." (118FW15)

Respondents often perceived people who traded door to door to be either part of a travelling community, and/or people who had travelled via the ferry from Ireland to Anglesey, thus implying these sellers were travelling through Anglesey rather than resident businesses. With the exception of one respondent who had been defrauded of money and equipment from dealing with a travelling salesman; all other respondents who raised this subject during interviews noted that as long as they did not involve themselves with these salesmen they were reasonably certain their business would be safe.

"I've seen...Am I allowed to call them gypsies or travellers I've seen travellers hanging on the gates there. Call the dog of mister, call the dog off, just because the great thing here is that they... when you've got an open we've got three farms, you know, in three different places. But you will see them, they used to drive in, see nobody about, and then they drive and... They would have their eyes in every shed. Just to "Mr Boss are you about boss, are you about, boss." And they will have seen, identify everything in the place while they were doing that, but those dogs stopped all that. But you know, and that's the problem. These opportunist thieves. You know, they drive in and if the doors are open "Boss are you there." You know, and they would go. That's the problem." (134FS06)

Not all respondents saw door-to-door sales people as an overt threat to their businesses but they all expressed a degree of caution around them.

"Touch wood, touch wood. We don't see them that often but you'll find here, the Irish people, the Irish...that they come in, they're selling generators and brand new things on the back of the van towards their stuff. It's fortunately, quite good stuff actually. But I don't see them as a threat because it's easier for them to sell something to a farmer, I mean genuine stuff, to make their money and their profit and then go home." (106FE04) 
This attitude was part of a broader mind-set on the part of respondents that the safest way to do business was with people in their communities who had good reputations and were established traders on Anglesey.

"Yeah, it's very seldom that you have to go outside the immediate area to get something done. You know, there are builders who do small jobs. And you know, like anything like there's the welding, the builder chap that we use as a carpenter as well. So, if you want to anything done in that line, you can get it done." (118FW015)

If an interviewee required additional workers or was seeking to employ someone outside of their family, with the exception of two respondents everyone hired from the local community. Where someone lived and who their family was played a key part in the hiring process for respondents. If the respondent knew who this person was or who their family members were they deemed trustworthy. This process was often discussed as a positive as it ensured the employment of someone the respondent could rely on both to be trustworthy and capable of working on the farm. During three interviews the respondents enquired as to the background of the researcher and whether or not they lived on Anglesey. Enquiries were also made as to the ability to speak Welsh or not (the researcher was bilingual). These enquires were often made during the beginning of interviews. One interview respondent noted how awareness of who is who in the local community could also be used to identify potentially dangerous or untrustworthy individuals. In five interviews respondents noted the presence of individuals or families who had been identified as potentially dangerous to their businesses. How respondents reacted to the presence of these people varied.

"See this is...this is something that we...we're very new to when we kind of lived here. It's a different environment where we lived in London, wasn't it? I know the outskirts of London well you know, thievery was there all the time. I'm not saying there's no thievery up here because there is. But you'll find here that, you get to know who the thieves are. You also get to know that if someone came in here and stole something and you were to ask questions around, it wouldn't take very long to find out who'd done it." (106FE04)

Local agricultural suppliers and companies were preferred by respondents in part for reasons of practicality and in part because they were able to gain a sense of their reliability from other farmers in the community.

“...you'd get to know. I mean, obviously in a community like this, if there's a farmer around who doesn't pay, it wouldn't take long to find out. We use a contact to the guys who's actually doing the baling this morning. He's done quite a big contract in business. If there's anybody around who doesn't pay, he will know. You know, I've had dealings 
Farmers' Experiences as Victims of Crime: An Exploratory Study on the Isle of Anglesey Holmes and Jones

with him himself or some other contractor he has contact with, will know. So, yeah that's as a good a means as any mode of getting to know... we're basically dealing with people we've known all the time we've been here. But again, yeah, I say there's no guarantee that its $100 \%$ fool proof. But neither is any other, any other system. I'd say, if people having these contractors don't know there's a problem somewhere then there probably isn't, they will know. And the first people that don't get paid are either the feed merchants or contractors. They seem to be the first ones if there's a problem somewhere and they can't pay, they don't pay the contractor for 12 months sort of thing. Word gets around." (118FW15)

When discussing how respondents dealt with accounting in their business all respondents (with the exception of one) reported using local accounting firms rather than large firms outside of Anglesey. This practice was representative of respondents trust in local organisations. In three interviews respondents noted that the farm accounts with local firms had been established before the respondent had begun working on the farm.

"He was my father-in-law's accountant 40 years ago and I have been with him ever since. In fact, he retired last year, so I saw somebody else who are on the same business." (108FN24)

\section{Division of responsibilities}

On this topic, respondents often noted that they were ultimately responsible for all aspects of their business even if they worked with family members or employees. The nature of farming was a topic which arose in several interviews where respondents noted the strong links between work life and family life. The location of their business within their own home often meant that respondents saw farming as more than a profession but also a way of life.

"For someone who works outside the door. My earliest commute, is about two seconds. (Laughter) And yes, I mean, I suppose you would really class the whole site as your home. Yeah. It's definitely not regarded as something separate. Yeah, you still around a shopping town or a garage or something like that. Yes. You go like for a certain number of hours a day and lock the door and come home. Well, no. If you're here well, the shop's open, isn't it? Yeah, you're always sort of doing something." (118FW15)

Despite this close link between family life and their work as farmers, the respondents interviewed often viewed themselves as the individuals solely responsible for the maintenance of the business. As the directors of the business, these respondents were often resistant to spending more time or energy on crime prevention as it was often seen as one expense amongst many. 
"That's the problem it's on the list but it's not that high up is it that's the difficulty and you only... budgets are getting so tight now it's difficult to say I'm going to spend this on security and get extra lights in so I feel safer there are more important things unfortunately." (028FC03)

Those interviewed who had not been the victim of crime themselves claimed that without being the victim of crime they would not prioritize crime prevention.

\section{Support in the community}

Views on the support available from the county council, Farmers Unions and the police varied, many respondents chose not to involve themselves with support networks unless there was an immediate problem. These views were more acute with regard to victim support, council support or any optional support offered by local government agencies.

"Well, from my point of view, I'm bold enough to go out there and find what I want. But I think, from a lot of people's point of view, then, it's not advertised enough. I don't think there's enough publicity to what is available for people out there. That's just a personal thing. I'm bold enough to get on the phone or on the internet and I will find out, and I will then say to people, 'Well, you know, this is available to you. I thought you can do this.' All that sort of thing. I think, you pick up things also, because I'm involved in $<$ a business interest group $>$. $<018 F N C 22 a>$ will go to the NFU meeting. So, you pick up things that way. But you do find yourself saying to people, 'Well, you know, this is available. That's available.' And they don't know. They haven't got a clue really. But that's just because that's me and bold and brassy about it." (018FNC22)

Several respondents referred to the lifestyle of a farmer as one which was very independent and resistant to seeking outside support or assistance. This was often discussed as being part of the mind-set farmers have.

\section{Attitudes towards the police}

With regard to the police opinions varied, several respondents reported minimal contact with the police in any capacity. A common response from respondents was that the police were not interacting enough with the communities they policed.

"We don't get a degree of involvement with the police. They've become more and more isolated from the community. We just pull our hair out at times, don't we? Because it's pathetic; there's so much information within the community." (106FE04) 
Farmers' Experiences as Victims of Crime: An Exploratory Study on the Isle of Anglesey Holmes and Jones

Of those who had cause to contact the police there were varied responses as to how effective the police had been in resolving issues. Additionally the lack of persistent or serious crimes against farmers meant that respondents were not motivated to build or improve the relationships they had with the police. When questioned about police initiatives to combat rural crime respondents had limited knowledge of current or previous efforts.

"Well again there was some talk of farmwatch, think thats gone. One other thing thats gone dead for some reason was the numbering the livestock trailers on their roofs that was a good idea because the police helicopters could see them a long way off for some reason they stopped that there was talk of it being done on the Anglesey show ground at one time didn't materialise." (067FW05)

"No, but in all fairness they did come here twice when the trailer went missing. But I hardly see them you know when we get our bill for the poll tax or whatever they call them there is that charge for the police and we all think hmmm where are they? You know we never see them do we, we hear them from the main road but we are lucky you know we are never bothered, hardly ever see anyone suspicious do we... It would be nice we probably see them once in a year driving past but thats about all We will see them once in a year driving past." (059FEC21)

Two issues emerged during the interviews with regard to the police, firstly that there was minimal contact with the police, which some respondents saw as a problem and others saw as simply a by-product of living in a rural area. Secondly, respondents would argue that there were practical limits to what could be achieved by the police.

"They can't do anything it is up to us to the individual to look after their place." (067FW05).

It could be argued that improvements with to regard intelligence-gathering within the local community by the police would be an area for policy development. It may prove difficult to gain significant improvements in terms of engagement with the police given that (according to this study) farmers often are not overly concerned with addressing criminal activity. This is in part due to scepticism over what the police can achieve and limited experience as victims of crime.

\section{Resolving problems through insurance claims}

The role of the police was in many ways to provide respondents with information that could be used to make an insurance claim. Crime was less of an issue if an item was insured and 
they could recoup their losses. The influence this had on working practices and crime prevention strategy was interesting as respondents would often make a note to avoid practices which would jeopardize an insurance claim.

"Tractors are never left with the key in them. The key is always taken out because if you leave the key and so, the insurance won't pay. If you take the key out and somebody nicks it, you're okay. So, that's a golden rule. Well, no vehicle is left with the key in it. We always take the key out of." (118FW15)

This attitude suggests that while farmers may be recorded as the victims of crime, as long as they have insurance on their property it will not produce a sense of being victimized or deprived. None of the respondents who had been the victim of a crime had sought assistance from victim support but they had all reported the loss with their insurance provider.

\section{Conclusion}

This study served as an exploration of farmer's experiences as victims of crime and their attitudes towards crime prevention. Responses from the survey and the interviews showed several interesting aspects of farmers' experiences on Anglesey. Respondents who took part in the study often had minimal or limited experience as victims of crime. The crime prevention response often adopted took into account the rural environment they lived in and was based on improving their chances of detecting trespassers (through motion activated lights and the barking of dogs). Interview respondents relied on local social networks within the community to determine who to work with and to identify potential threats to their businesses. This practice resulted in farmers trying to avoid problems from employees, suppliers or service providers (such as accountants) through knowledge of their environment and community.

\section{"If you live on Anglesey it's basically word of mouth."(139FW13).}

National Farmers Union Mutual's rural crime survey (2014) indicated that tools, quad bikes and fuel were the most commonly targeted items for theft. The theft of these items was an issue for respondents in particular quad bikes emerged as topic of conversation with several farmers. Farmers in this study often downplayed the impact of crime and their victimisation. This was done through reliance on insurance policies and the view that no individual incidents of crime will completely destroy their business.

While Anglesey is a rural county in Wales it is not a remote location. Transportation routes enable a flow of people on and off the island. Despite this, respondents displayed several insular 
traits relying on local community for support and displaying a degree of mistrust to those viewed as outsiders or non-residents of the area. Mistrust of people who were not residents of the community did not lead to an increase in security or preoccupation with security.

Instead, this reality was accompanied by an attitude that crime prevention was one of many priorities and not something they wanted to focus on as it may undermine their lifestyle. Many respondents reported that farming was not only a profession, but also a way of life and they did not want to increase security and change the way they worked or lived their lives.

"Yeah. We don't want to live like Fort Knox here, so you've got to accept that there's a degree of vulnerability about all premises. The only thing that's...I've said to you in the very beginning... we are not presented here as like Fort Knox full of gold, so people are going to be fairly sceptical about coming here and are hoping to steal something really worthwhile. It just won't happen." (106FE04)

\section{Acknowledgments}

The authors would like to acknowledge the support of both Aberystwyth and Bangor University for their support during this study and the co-operation and involvement of our respondents, Menter Mon and Anglesey County Council. 


\section{Reference List}

Anderson, K. M., McCall, M. (2005). Farm crime in Australia. Canberra, Australian Institute of Criminology, Retrieved 28/04/2015 from www.aic.gov.au/publications/current\%20series/cfi/101-120/cfi119.aspx

Barclay, E. M. (2001). A review of related literature on agricultural crime. Institute for Rural Futures, University of New England, Retrived 23/04/15 from www.criminologyresearchcouncil.gov.au/reports/barclay.pdf

Bouffard A. L., Muftíc R.L. (2006). The "rural mystique": Social disorganization and violence beyond urban communities. Western Criminology Review, 7, 56-66.

Carcach, C. (2002). Farm Victimisation Australia. Trends and Issues in Crime and Criminal Justice, No. 235, Australian Institute of Criminology, Canberra 21-22 June, 2001.

Donnermeyer, J.F., Barclay E. M. (2005). The policing of farm crime. Police Practice and Research, 6, 3-17, https://doi.org/10.1080/15614260500046913

Home Office (2009). Business and Retail Crime, Retrieved 09/03/15 from http://www.crimereduction.homeoffice.gov.uk/toolkits/br020201.htm

Jones, J. (2010). The neglected problem of farm crime: an exploratory study, Safer Communities, 9, 36-44, https://doi.org/10.5042/sc.2010.0013

Jones, J. (2011). Recording and Responding to Farm Crime: A National Study of Police Forces in England and Wales, Aberystwyth University.

Mears, D.P., Scott, M.L., Bhati, A.S. (2007). Opportunity theory and agricultural crime victimization. Rural Sociology, 72, 151-184, https://doi.org/10.1526/003601107781170044

National Assembly for Wales Commission (2008). Key Statistics for Isle of Anglesey, Retrieved 18/05/2015 http:/www.assembly.wales/NAfW\%20Documents/anglesey.pdf\%20$\% 2018042008 /$ anglesey-English.pdf

NFU Mutual (2004). Perception of rural crime at odds with the statistics, NFU Mutual Press Release, Published on $4^{\text {th }}$ July, 2004.

NFU Mutual, (2014). NFU Mutual Rural Crime Survey 2014, Retrieved 01/03/15 http://www.nfumutual.co.uk/farming/initiatives/rural-crime/ 